\title{
Pengembangan E-Modul Pengayaan Materi Debat Berbasis Software Sigil untuk Pembelajaran Bahasa Indonesia Kelas X SMA di Purbalingga
}

\author{
Development of E-Module Enrichment of Sigil Software-Based Debate Materials for \\ Indonesian Language Learning X Grade of High School in Purbalingga \\ ${ }^{1)}$ Catur Andiyanto, ${ }^{2)}$ Santhy Hawanti, ${ }^{3)}$ Kuntoro \\ ${ }^{1)}$ SMA Negeri 1 Purbalingga \\ ${ }^{2,3)}$ Universitas Muhammadiyah Purwokerto \\ *email: catur04051986@gmail.com, santhyhawantiump@ gmail.com, kuntorosutaryo@gmail.com
}

\begin{abstract}
Histori Artikel:
ABSTRAK

Diajukan:

$05 / 09 / 2021$

Diterima:

$09 / 10 / 2021$

Diterbitkan:

08/12/2021

Penelitian dan pengembangan bahan ajar berupa E-Modul Pengayaan Materi Debat Berbasis Software Sigil ini bertujuan agar tercapai pembelajaran bahasa Indonesia yang efektif, efisien, dan menarik. Metode penelitian ini adalah Research and Development $(R \& D)$ berdasarkan model ADDIE. Subyek penelitian ini adalah siswa SMA Negeri 1 Purbalingga dan SMA Negeri 1 Kutasari. Data penelitian diperoleh dengan teknik wawancara, angket, observasi, dan tes. Validasi melibatkan dua ahli materi dan dua ahli media dengan melalui beberapa revisi diperoleh hasil akhirnya menunjukan kategori valid (layak digunakan). Tahap uji kemenarikan skala kecil (15 responden) dan skala besar (60 responden) diperoleh hasil keduanya dikategorikan "sangat menarik". Uji keefektifan produk dengan uji effect size diperoleh nilai akhir hasil belajar (posttest) lebih tinggi dari nilai awal (pretest) sehingga digolongkan cukup efektif. Berdasarkan hasil tersebut dapat disimpulkan bahwa E-Modul Pengayaan Materi Debat Berbasis Software Sigil dikategorikan layak dan cukup efektif untuk dijadikan alat bantu pembelajaran bahasa Indonesia SMA di Purbalingga.
\end{abstract}

Kata kunci: E-Modul Pengayaan, Materi Debat, Software Sigil

\begin{abstract}
The research and development of teaching materials in the form of a Debate Materials Enrichment E-module based on Sigil Software aimed at making Indonesian language learning more effective, efficient, and enjoyable. The Research and Development $(R \& D)$ approach was employed in this study, which was based on the ADDIE model. Students from SMA Negeri 1 Purbalingga and SMA Negeri 1 Kutasari were the subjects of this study. Interviews, questionnaires, observations, and tests were used to collect data for the study. Two material experts and two media experts were participated in the validation. The final result showed a valid category after multiple changes (fit for use). The results of the short scale (15 respondents) and large scale (60 respondents) attractiveness tests were both categorized as "Very Interesting." The product's effectiveness was determined by an effect size test, which revealed that the final value of learning outcomes (posttest) was greater than the initial value (pretest), indicating that it was quite effective. According to the findings, The Debate Materials Enrichment E-module based on Sigil Software was categorized as practicable and effective enough to be employed as an Indonesian learning aid for Senior High School in Purbalingga.
\end{abstract}

Keywords: Enrichment E-Module, Debate Material, Sigil Software 


\section{PENDAHULUAN}

Kompetensi dalam pembelajaran di era sekarang ini masih ditemukan beberapa konsep-konsep lama yang sudah tidak relevan untuk diterapkan pada abad 21 sekarang ini. Hal itu karena tuntutan kompetensi dalam pembelajaran di abad 21 ini harus diselaraskan dengan pendekatan yang sekarang digunakan yaitu pendekatan saintifik $5 \mathrm{M}$ yang sudah diprogramkan oleh pemerintah. Dalam pendekatan saintifik $5 \mathrm{M}$ ini di dalamnya peserta didik harus mampu mengamati, menanyakan, mengumpulkan informasi, menalar, dan mengomunikasikan. Dengan penerapan pendekatan saintifik $5 \mathrm{M}$ tersebut akan berdampak positif kepada peserta didik dalam keahlian $4 \mathrm{C}$ yaitu communication, collaborration, critical thinking and problem solving, creativity and innovation. Tetapi pada kenyataanya sekarang ini masih ditemukan konsep pembelajaran yang belum sesuai dengan program pemerintah tersebut. Untuk mendukung program tersebut, konsep dalam pembelajaran juga harus ada pembaharuan yang disesuaikan dengan abad 21 sekarang ini guna memperoleh hasil yang terbaik dalam mendidik siswa.

Tujuan pembelajaran harus dapat memfasilitasi siswa dalam menumbuhkan dan mengembangkan kesadaran belajar, sehingga mampu melakukan olah pikir, rasa, dan raga dalam memecahkan masalah kehidupan di dunia nyata. Inovasi akan lahir apabila ada sesuatu yang terkait dengan kebutuhan. Dengan demikian, motivasi untuk belajar menjadi semakin besar dan kuat. (Uno, Hamzah B. Sutardjo Atmowidjoyo, dan Nina Lamatenggo. 2018: 261). Dengan besarnya motivasi belajar siswa berarti menandakan guru mampu menguasai berbagai kemampuan dalam membuat inovasi yang dibutuhkan siswanya. Termasuk dalam hal kemampuan teknologi untuk guru harus menguasai teknologi pendidikan yang dipakai dalam proses pembelajaran karena sudah jelas sekali kalau teknologi memiliki berbagai dampak positif bagi pendidikan.

Teknologi memiliki dampak positif bagi pendidikan terutama dalam hal kemajuan Teknologi Informatika dan Komputer. Kemajuan TIK memungkinkan berkembangnya kelas virtual atau kelas yang berbasis teleconference yang tidak mengharuskan sang pendidik dan peserta didik berada dalam satu ruangan. Dampak dari hal ini yaitu guru bukanlah satu-satunya sumber ilmu pengetahuan, sehingga siswa dalam belajar tidak perlu terlalu terpaku terhadap informasi yang diajarkan oleh guru, tetapi juga bisa mengakses materi pelajaran langsung dari internet, oleh karena itu guru disini bukan hanya sebagai pengajar, tetapi juga sebagai pembimbing siswa untuk mengarahkan dan memantau jalannya pendidikan, agar siswa tidak salah arah dalam menggunakan media informasi dan komunikasi dalam pembelajaran (Wahyudin. 2018: 53).

Berdasarkan hasil wawancara ke beberapa guru dan siswa di SMA Negeri 1 Purbalingga dan SMA Negeri 1 Kutasari terdapat beberapa per-masalahan yang masih ditemukan sekarang ini bahwa pendidik umumnya masih banyak memakai media yang lama yaitu hanya menggunakan buku paket tercetak. Ditambah lagi masih ada sekolah yang jumlah buku paket tercetaknya belum sebanyak jumlah siswa di sekolah tersebut sehingga siswa pinjamnya bergantian. Pendidik masih jarang menggunakan media pembelajaran elektronik dalam proses pembelajaran yang dapat diakses di komputer ataupun android. Hal tersebut selaras dari hasil instrumen analisis kebutuhan media pembelajaran siswa diperoleh informasi secara umum bahwa siswa mayoritas memiliki komputer atau laptop dan juga android yang seharusnya dapat digunakan untuk membuka 
berbagai media pembelajaran salah satunya yaitu buku elektronik ataupun modul elektronik yang dapat diakses di mana saja dan lebih praktis dibandingkan kalau hanya menggunakan buku tercetak.

Berdasarkan hasil identifikasi permasalahan, maka pengembangan sumber belajar yang lebih mudah diakses dengan keberadaan teknologi menjadi sangat penting. Hasil wawancara dan analisis kebutuhan menunjukkan bahwa salah satu sumber belajar yang bisa dengan mudah diakses siswa adalah dengan mengembangkan $e$-modul. yang lebih efektif, efisien, dan mengutamakan kemandirian siswa. Salah satu aplikasi yang tepat untuk membuat $e$-modul tersebut adalah dengan menggunakan Software Sigil. Software Sigil merupakan editor untuk epub yang gratis dan dapat digunakan untuk semua orang (legal). Dengan segala kemudahan yang diberikan sigil ini dapat dijadikan salah satu pemecahan masalah yang ada dalam dunia pendidikan terutama pada bahan ajar berupa media pembelajaran seperti modul elektronik (E-modul) dengan format epub sebagai sumber materi yang memiliki nilai ekonomis bagi kalangan pelajar pembelajaran.

Rumusan masalah yang diajukan untuk penelitian adalah Bagaimana analisis kebutuhan peserta didik dan guru dalam pengembangan E-Modul, Bagaimana proses pengembangan E-Modul, Bagaimana kualitas E-Modul, Bagaimana respon guru terhadap pengembangan E-Modul, dan Bagaimana respon peserta didik terhadap pengembangan E-Modul Pengayaan Materi Debat Berbasis Software Sigil untuk Pembelajaran Bahasa Indonesia Kelas X SMA di Purbalingga. Berdasarkan rumusan masalah yang telah ditetapkan, maka tujuan penelitian ini adalah untuk mengetahui hasil analisis kebutuhan peserta didik dan guru dalam pengembangan E-Modul, untuk mengetahui proses pengembangan E-Modul, kualitas E-Modul, respon guru terhadap pengembangan E-Modul, dan untuk mengetahui respon peserta didik terhadap pengembangan E-Modul Pengayaan Materi Debat Berbasis Software Sigil untuk Pembelajaran Bahasa Indonesia Kelas X SMA di Purbalingga.

Manfaat penelitian dan pengembangan adalah dari segi teoretis dan praktis. Hasil penelitian ini secara teoretis diharapkan dapat memperkaya khasanah ilmu pengetahuan khususnya ilmu tentang Media E-Modul Pengayaan Materi Debat Berbasis Software Sigil untuk Pembelajaran Bahasa Indonesia Kelas X SMA di Purbalingga. Manfaat praktis bagi penelitia adalah mampu memberikan pengalaman langsung dalam pengembangan $e$ modul pengayaan materi debat berbasis software sigil untuk pembelajaran Bahasa Indonesia. Manfaat praktis bagi peserta didik adalah diharapkan peserta didik dapat belajar mandiri dengan menggunakan e-modul dimanapun dan kapanpun dan dapat digunakan sebagai alternatif pembelajaran bagi sekolahsekolah. Sedangkan manfaat praktis bagi pendidik atau guru adalah menjadi bahan pertimbangan untuk menggunakan e-modul berbasis Software sigil pada proses pembelajaran serta dapat memberikan ketertarikan pada peserta didik terhadap pembelajaran bahasa Indonesia.

Teori-teori yang dijadikan pijakan dalam penelitian dan pengembangan ini yang pertama adalah teori tentang e-modul pengayaan. E-Modul adalah salah satu media yang efektif, efisien, dan mengutamakan kemandirian siswa. Vembriato mengatakan bahwa modul adalah paket pengajaran yang memuat suatu unit konsep dari bahan pengajaran. Memasuki era teknologi, banyak teknologi baru yang mampu memberikan suatu informasi lebih banyak. Teknologi berkembang seiring zaman yang akan terus berkembang. (Ramadhana Agung Pratama, 
Saida Ulfa, and Dedi Kuswandi, 2018:772). Secara umum pengayaan dapat diartikan sebagai pengalaman atau kegiatan peserta didik yang melampaui persyaratan minimal yang ditentukan oleh kurikulum dan tidak semua peserta didik dapat melakukannya. Kegiatan pengayaan materinya adalah kegiatan yang diberikan kepada peserta didik kelompok cepat dalam memanfaatkan kelebihan waktu yang dimilikinya sehingga mereka memiliki pengetahuan yang lebih kaya dan keterampilan yang lebih baik. Kunandar (2013: 240) menjelaskan bahwa program pengayaan adalah program pembelajaran yang diberikan kepada peserta didik yang belajar lebih cepat.

Selanjutnya, teori tentang Software Sigil. Sigil adalah aplikasi untuk manajemen dan pembuatan Digital Book dengan format Epub. Dengan menggunakan Sigil, pengembang dapat membuat digital book sesuai dengan yang diinginkan. Sigil mendukung format text, html dan format epub yang dapat menciptakan buku digital lebih bervariasi. Menurut Nunuk Suryani dkk (2018: 88-89) menyatakan bahwa lebih dari 20 tools yang bisa digunakan dengan fungsi yang beragam. Sigil juga dilengkapi tool yang bisa digunakan untuk memeriksa kesalahan pada file $e P u b$ tersebut dengan cara klik pada "tombol centang berwarna hijau" untuk memverifikasi apakah sudah bebas dari kesalahan atau belum sebelum didistribusikan. Sigil juga didukung 15 macam bahasa serta dapat berjalan pada sistem operasi Windows, Linux, Mac, dan android.

\section{METODE}

Lokasi penelitian ini dipilih sesuai dengan tujuan dan disengaja sesuai kebutuhan. Produk berupa media pembelajaran yang dihasilkan diperuntukkan kepada peserta didik kelas X SMA di Purbalingga. Lokasi penelitian yang dipilih adalah SMA Negeri 1 Purbalingga dan SMA Negeri 1 Kutasari. Sedangkan waktu penelitian ini dilaksanakan pada semester 2 tahun ajaran 2020/2021.
Jenis penelitian yang digunakan adalah metode penelitian dan pengembangan Research and Development (R\&D). Menurut Sugiyono (2013: 407) metode penelitian dan pengembangan atau dalam bahasa Inggrisnya Research and Development adalah metode penelitian yang digunakan untuk menghasilkan produk tertentu, dan menguji keefektifan produk tersebut. Untuk dapat menghasilkan produk tertentu digunakan penelitian yang bersifat analisis kebutuhan dan untuk menguji keefektifan produk tersebut supaya dapat berfungsi di masyarakat luas, maka diperlukan penelitian untuk menguji keefektifan produk tersebut. Jadi penelitian dan pengembangan bersifat longitudinal (bertahap bisa multy years). Ada beberapa jenis model penelitian dan pengembangan R\&D (Research and Development) dan salah satunya yaitu model ADDIE. Tujuan pemilihan model ADDIE sebagai model pengembangan media adalah untuk menghasilkan produk dan prosedur yang diuji coba di lapangan secara sistematis, dievaluasi dan diperbaiki sehingga memenuhi kriteria yang diharapkan terkait keefektifan, kualitas, dan standar yang ditetapkan. (Nunuk Suryani, Achmad Setiawan, dan Aditin Putria, 2018:128).

Subjek uji coba penelitian ini yaitu Peserta didik kelas $\mathrm{X}$ di SMA Negeri Purbalingga dan SMA Negeri 1 Kutasari. Uji coba pada penelitian ini dilakukan dengan uji coba kemenarikan dan keefektifan. Jenis data dalam pelaksanaan penelitian dan pengembangan ini yaitu data kuantitatif dan data kualitatif. Teknik pengumpulan data yang digunakan yaitu wawancara, kuisioner (angket), dan metode tes. Teknik analisis data pada penelitian ini yaitu teknik analisis data berupa validasi data $e$-modul. Sedangkan uji ahli atau validator produk e-modul dalam penelitian dan pengembangan ini melibatkan beberapa orang yaitu validator ahli materi dan ahli media pembelajaran yang terdiri dari 
dosen dan praktisi. Tujuan uji validasi yaitu menilai kelayakan produk yang dikembangkan sebagai media pembelajaran. Uji validasi ini menguji kesesuaian materi modul, aspek keterbacaan dan konstruksi. Penilaian uji desain dan uji materi dilakukan menggunakan angket. Instrumen yang digunakan memiliki 4 jawaban, sehingga skor penilaian total menggunakan rumus sebagai berikut:

$$
\begin{aligned}
\bar{x}=\sum_{x_{i}}^{n} \frac{x_{i}}{n}, & \text { denganx }_{i} \\
& =\frac{\text { jumlah skor }}{\text { skor maksimal }} \times 4
\end{aligned}
$$

Keterangan:

$. \bar{x}=$ nilai rata-rata akhir

$. x_{i}=$ jumlah skor jawaban penilaian

$\mathrm{n}=$ jumlah validator

\section{HASIL DAN PEMBAHASAN}

\section{A. Hasil Penelitian Pengembangan E-Modul} Pengayaan Materi Debat Berbasis Software Sigil untuk Pembelajaran Bahasa Indonesia Kelas X SMA di Purbalingga

Pengembangan media pembelajaran berupa e-modul tersebut dilakukan melalui tahapan yang terdapat dalam model penelitian ADDIE yaitu meliputi analysis, design, development, implementation, evaluation.

Adapun berikut pemaparan dari tiap-tiap tahap yang dilalui.

\section{Tahap Analysis (Analisis)}

a Analisis Kebutuhan

1) Analisis kebutuhan siswa

Angket hasil analisis kebutuhan siswa dapat dilihat hasil wawancara awal kebutuhan pada 15 responden peserta didik.

2) Analisis kebutuhan guru

Analisis kebutuhan guru

$\begin{array}{lll}\text { dilaksanakan } & & \begin{array}{l}\text { dengan } \\ \text { menyebarkan } \\ \text { empat guru. }\end{array} \\ & \text { angket } & \text { kepada }\end{array}$

b. Analisis Kurikulum

Dilakukan analisis kurikulum yaitu untuk menentukan materi yang digunakan dalam e-modul. Terdapat 4 Kompetensi Dasar yang harus dicapai peserta didik yaitu: KD 3.12, $\mathrm{KD}$ 4.12, KD 3.13, dan KD 4.13 tentang materi bahasa Indonesia.

c. Analisis Karakteristik Peserta Didik

E-Modul sebagai bahan ajar yang digunakan dalam pembelajaran harus memperhatikan karakter peserta didik, sehingga sesuai dengan peserta didik. Karakteristik peserta didik yang perlu diperhatikan antara lain kemampuan akademik individu, motivasi belajar, fisik, latar belakang ekonomi dan sosial, pengalaman belajar sebelumnya, dsb. Analisis karakteristik tersebut, peneliti menyesuaikan isi e-modul sesuai dengan karakteristik peserta didik.

\section{Tahap Design (Perancangan)}

a Penyusunan Kerangka E-Modul

Tampilan desain $e$-modul meliputi:

1) Bagian pembuka

Bagian pertama yaitu cover berisi tulisan "E-Modul Pengayaan Materi Debat"

2) Bagian isi e-modul (materi)

Bagian isi e-modul berisi petunjuk penggunaan, kompetensi dasar yang harus dicapai, peta konsep dan dilanjutkan materi debat bahasa Indonesia. Pada materi debat bahasa Indonesia terdiri dari tujuan pembelajaran, uraian materi, rangkuman, 
penugasan mandiri, latihan soal, penilaian diri, dan evaluasi.

3) Bagian penutup

Bagian terakhir e-modul adalah referensi daftar pustaka.

b. Perancangan Penyajian Materi

Materi diambil dari buku paket yang digunakan guru dan dari sumbersumber yang terpercaya. Perancangan Instrumen yang dirancang yaitu berupa angket yang aspek-aspeknya telah disesuaikan. Perancangan instrument penilaian diawali dengan penyusunan angket penilaian yang diberikan kepada para para ahli untuk mengetahui kualitas produk. Selain itu untuk siswa diberikan angket agar mengetahui respon siswa terhadap bahan ajar yang telah dikembangkan dan juga tes keefektifan $e$-modul untuk siswa. Adapun soal pretest dan posttest berbentuk pilihan ganda, dimana soal tersebut mengacu pada kompetensi dasar.

\section{Tahap Development (Pengembangan)}

E-modul akan dibuat pada tahap ini sesuai rancangan pada tahap design.

\section{a Pembuatan E-Modul}

1) Bagian pembuka (intro)

Penulis mengembangkan bagian cover pada bagian pembuka yang dirancang menggunakan software corel draw.

B. Gambar 1. (Tampilan Penyusun E-Modul)
PENYUSUN E-MODUL

(DEBAT BAHASA INDONESIA)

Penyusun :

Catur Andiyanto, S.Pd

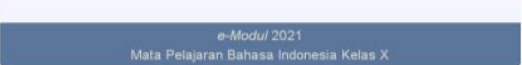

Pengembangan pada bagian penyusun $e$-modul dibuat dengan tulisan nama penyusunnya bergerak secara otomatis dari bawah ke atas menggunakan pengaturan encoding

C. Gambar 2. (Tampilan Daftar

Isi)

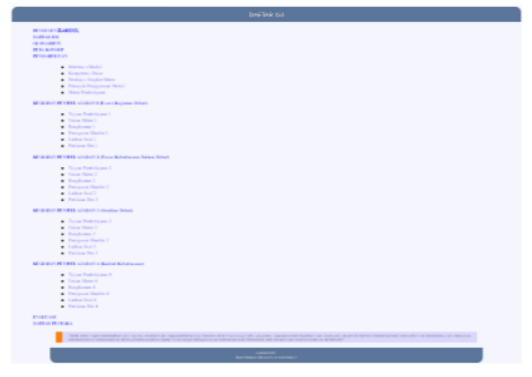

Bagian daftar isi dibuat dengan menu yang ketika diklik akan masuk link ke bagian yang dipilih dengan pengaturan encoding

2) Bagian isi e-modul (materi)

Bagian isi e-modul berisi materi sesuai daftar isi dengan didukung gambar peta konsep.

3) Bagian Penutup

Bagian penutup berisi daftar pustaka.

\section{b. Hasil Evaluasi Validator}

1) Evaluasi Ahli Media

a) Evaluasi Ahli Media Validator I 
Catur Andiyanto, Santhy Hawanti, Kuntoro

Pengembangan E-Modul Pengayaan Materi Debat Berbasis Software Sigil untuk Pembelajaran Bahasa Indonesia Kelas X SMA di Purbalingga

D. Tabel 1 .

\begin{tabular}{|c|c|c|c|}
\hline No & Bagian & $\begin{array}{l}\text { Komentar } \\
\text { (Jenis } \\
\text { Kesalahan) }\end{array}$ & $\begin{array}{l}\text { Saran } \\
\text { Perbaikan }\end{array}$ \\
\hline 1 & $\begin{array}{l}\text { Efesiensi } \\
\text { Media }\end{array}$ & $\begin{array}{l}\text { Perbaiki bagian } \\
\text { menu program } \\
\text { karena ada link } \\
\text { yang tidak } \\
\text { sinkron }\end{array}$ & $\begin{array}{l}\text { Sebaiknya } \\
\text { diperbaiki } \\
\text { bagian menu } \\
\text { program agar } \\
\text { semua link bisa } \\
\text { sinkron }\end{array}$ \\
\hline 2 & $\begin{array}{l}\text { Efesiensi } \\
\text { Media }\end{array}$ & $\begin{array}{l}\text { Perbaiki } \\
\text { programnya } \\
\text { agar keluar } \\
\text { masuknya lebih } \\
\text { mudah }\end{array}$ & $\begin{array}{l}\text { Sebaiknya } \\
\text { diperbaiki } \\
\text { programnya } \\
\text { agar keluar } \\
\text { masuknya lebih } \\
\text { mudah }\end{array}$ \\
\hline 3 & $\begin{array}{l}\text { Fungsi } \\
\text { Tombol }\end{array}$ & $\begin{array}{l}\text { Perbaiki } \\
\text { struktur } \\
\text { tombolnya agar } \\
\text { lebih mudah }\end{array}$ & $\begin{array}{l}\text { Sebaiknya } \\
\text { diperbaiki } \\
\text { struktur } \\
\text { tombolnya agar } \\
\text { lebih mudah }\end{array}$ \\
\hline 4 & Grafis & $\begin{array}{l}\text { Perbaiki } \\
\text { kesesuaian } \\
\text { pemilihan } \\
\text { background }\end{array}$ & $\begin{array}{l}\text { Sebaiknya } \\
\text { diperbaiki } \\
\text { kesesuaian } \\
\text { pemilihan } \\
\text { background }\end{array}$ \\
\hline 5 & Grafis & $\begin{array}{l}\text { Perbaiki } \\
\text { kesesuaian } \\
\text { warna }\end{array}$ & $\begin{array}{l}\text { Sebaiknya } \\
\text { diperbaiki } \\
\text { kesesuaian } \\
\text { warna }\end{array}$ \\
\hline 6 & Grafis & $\begin{array}{l}\text { Perbaiki } \\
\text { kemenarikan } \\
\text { sajian gambar }\end{array}$ & $\begin{array}{l}\text { Sebaiknya } \\
\text { diperbaiki } \\
\text { kemenarikan } \\
\text { sajian gambar }\end{array}$ \\
\hline
\end{tabular}

b) Evaluasi Ahli Media Validator II

E.

Tabel 2.

\begin{tabular}{|l|l|l|l|}
\hline No & Bagian & $\begin{array}{l}\text { Komentar } \\
\text { (Jenis } \\
\text { Kesalahan) }\end{array}$ & $\begin{array}{l}\text { Saran } \\
\text { Perbaikan }\end{array}$ \\
\hline $\mathbf{1}$ & $\begin{array}{l}\text { Efesiensi } \\
\text { Media }\end{array}$ & $\begin{array}{l}\text { Keluar } \\
\text { masuknya } \\
\text { program harus } \\
\text { dipermudah }\end{array}$ & $\begin{array}{l}\text { Sebaiknya di- } \\
\text { perbaiki prog- } \\
\text { ramnya agar ke- } \\
\text { luar masuknya } \\
\text { lebih mudah }\end{array}$ \\
\hline $\mathbf{2}$ & Grafis & $\begin{array}{l}\text { Warnanya } \\
\text { perlu } \\
\text { disesuaikan }\end{array}$ & $\begin{array}{l}\text { Sebaiknya di- } \\
\text { perbaiki kesesu- } \\
\text { aian warnanya }\end{array}$ \\
\hline $\mathbf{3}$ & Grafis & $\begin{array}{l}\text { Sajian gambar } \\
\text { perlu dibuat } \\
\text { yang menarik }\end{array}$ & $\begin{array}{l}\text { Sebaiknya di- } \\
\text { perbaiki keme- } \\
\text { narikan sajian } \\
\text { gambarnya }\end{array}$ \\
\hline
\end{tabular}

2) Evaluasi Ahli Materi
F. Tabel 3.

\begin{tabular}{|l|l|l|l|}
\hline No & Bagian & $\begin{array}{l}\text { Komentar } \\
\text { (Jenis } \\
\text { Kesalahan) }\end{array}$ & $\begin{array}{l}\text { Saran } \\
\text { Perbaikan }\end{array}$ \\
\hline 1 & Materi & $\begin{array}{l}\text { Perbaiki } \\
\text { penulisan } \\
\text { ejaannya } \\
\text { supaya baik } \\
\text { dan benar }\end{array}$ & $\begin{array}{l}\text { Sebaiknya } \\
\text { diperbaiki } \\
\text { penulisan } \\
\text { ejaannya supaya } \\
\text { baik dan benar }\end{array}$ \\
\hline 2 & Materi & $\begin{array}{l}\text { Perbaiki } \\
\text { kalimat pada } \\
\text { bagian } \\
\text { petunjuk } \\
\text { penggunaan } \\
e-\text { modul } \\
\text { karena kurang } \\
\text { mudah } \\
\text { dipahami }\end{array}$ & $\begin{array}{l}\text { Sebaiknya } \\
\text { kalimat pada } \\
\text { bagian petunjuk } \\
\text { penggunaan } e- \\
\text { modul diperbaiki } \\
\text { dan diperjelas } \\
\text { lagi karena } \\
\text { kurang mudah } \\
\text { dipahami }\end{array}$ \\
\hline 3 & Materi & $\begin{array}{l}\text { Contoh } \\
\text { videonya hanya } \\
\text { dari youtube, } \\
\text { belum ada } \\
\text { tambahan } \\
\text { contoh siswa } \\
\text { dari sekolah di } \\
\text { Purbalingga }\end{array}$ & $\begin{array}{l}\text { Sebaiknya } \\
\text { dalam e- modul } \\
\text { ditambah contoh } \\
\text { video siswa yang } \\
\text { asalnya dari se- } \\
\text { kolah di Purba- } \\
\text { lingga supaya sis- } \\
\text { wa lebih tertarik } \\
\text { mempelajari e- } \\
\text { modulnya }\end{array}$ \\
\hline
\end{tabular}

b) Evaluasi Ahli Materi Validator II

G. Tabel 4 .

\begin{tabular}{|l|l|l|l|}
\hline No & Bagian & $\begin{array}{l}\text { Komentar } \\
\text { (Jenis } \\
\text { Kesalahan) }\end{array}$ & $\begin{array}{l}\text { Saran } \\
\text { Perbaikan }\end{array}$ \\
\hline 1 & Materi & $\begin{array}{l}\text { Perbaiki } \\
\text { penulisan } \\
\text { yang salah } \\
\text { ketik dan juga } \\
\text { yang kurang } \\
\text { tanda baca }\end{array}$ & $\begin{array}{l}\text { Sebaiknya } \\
\text { diperbaiki } \\
\text { penulisan yang } \\
\text { salah ketik dan } \\
\text { juga yang kurang } \\
\text { tanda bacanya }\end{array}$ \\
\hline 2 & Materi & $\begin{array}{l}\text { Contoh foto } \\
\text { atau } \\
\text { gambarnya } \\
\text { jangan hanya } \\
\text { satu }\end{array}$ & $\begin{array}{l}\text { Sebaiknya da- } \\
\text { lam e- modul di- } \\
\text { tambah contoh } \\
\text { foto atau gam- } \\
\text { barnya supaya } \\
\text { siswa lebih ter- } \\
\text { tarik mempelajari } \\
\text { e-modulnya }\end{array}$ \\
\hline 3 & Materi & $\begin{array}{l}\text { Contoh } \\
\text { videonya } \\
\text { jangan hanya } \\
\text { satu }\end{array}$ & $\begin{array}{l}\text { Sebaiknya da- } \\
\text { lam } e \text {-modul di- } \\
\text { tambah contoh } \\
\text { video nya supaya } \\
\text { siswa lebih terta- } \\
\text { rik mempelajari } \\
e-\text {-modulnya }\end{array}$ \\
\hline
\end{tabular}

a) Evaluasi Ahli Materi Validator I 
Catur Andiyanto, Santhy Hawanti, Kuntoro

Pengembangan E-Modul Pengayaan Materi Debat Berbasis Software Sigil untuk Pembelajaran Bahasa Indonesia Kelas X SMA di Purbalingga

\section{c. Hasil Penilaian Angket Validasi Tahap I}

1) Penilaian Angket Validasi Ahli Materi Tahap 1

H. Tabel 5. (Hasil Penilaian Angket Validasi Tahap 1 oleh Ahli Materi)

\begin{tabular}{|c|c|c|c|c|}
\hline \multirow{2}{*}{$\mathrm{NO}$} & \multirow{2}{*}{ Aspek } & \multirow{2}{*}{ Analisis } & \multicolumn{2}{|c|}{ Validator } \\
\hline & & & $\begin{array}{c}\text { Valida } \\
\text { tor } 1\end{array}$ & $\begin{array}{c}\text { Valida } \\
\text { tor } 2\end{array}$ \\
\hline \multirow[t]{5}{*}{1} & \multirow{5}{*}{$\begin{array}{l}\text { Keses } \\
\text { uaian } \\
\text { materi }\end{array}$} & $\Sigma$ Skor & 6 & 6 \\
\hline & & $\begin{array}{l}\text { Skor } \\
\text { Maksimal }\end{array}$ & 8 & 8 \\
\hline & & $\bar{x}_{i}$ & 3 & 3 \\
\hline & & $\bar{x}$ & \multicolumn{2}{|c|}{3} \\
\hline & & Kriteria & \multicolumn{2}{|c|}{ Cukup Valid } \\
\hline \multirow[t]{5}{*}{2} & \multirow{5}{*}{$\begin{array}{l}\text { Keaku } \\
\text { ratan } \\
\text { materi }\end{array}$} & $\Sigma$ Skor & 14 & 16 \\
\hline & & $\begin{array}{l}\text { Skor } \\
\text { Maksimal }\end{array}$ & 20 & 20 \\
\hline & & $\bar{x}_{i}$ & 2,8 & 3,2 \\
\hline & & $\bar{x}$ & \multicolumn{2}{|c|}{3} \\
\hline & & Kriteria & \multicolumn{2}{|c|}{ Cukup Valid } \\
\hline \multirow[t]{5}{*}{3} & \multirow{5}{*}{$\begin{array}{l}\text { Men } \\
\text { doro } \\
\text { ng } \\
\text { Kein } \\
\text { ginta } \\
\text { huan }\end{array}$} & $\Sigma$ Skor & 6 & 7 \\
\hline & & $\begin{array}{l}\text { Skor } \\
\text { Maksimal }\end{array}$ & 8 & 8 \\
\hline & & $\bar{x}_{i}$ & 3 & 3,5 \\
\hline & & $\bar{x}$ & \multicolumn{2}{|c|}{3,25} \\
\hline & & Kriteria & \multicolumn{2}{|c|}{ Cukup Valid } \\
\hline \multirow[t]{5}{*}{4} & \multirow{5}{*}{$\begin{array}{l}\text { Tekni } \\
\mathrm{k} \\
\text { Penyaj } \\
\text { ian }\end{array}$} & $\Sigma$ Skor & 3 & 3 \\
\hline & & $\begin{array}{l}\text { Skor } \\
\text { Maksimal }\end{array}$ & 4 & 4 \\
\hline & & $\bar{x}_{i}$ & 3 & 3 \\
\hline & & $\bar{x}$ & \multicolumn{2}{|c|}{3} \\
\hline & & Kriteria & \multicolumn{2}{|c|}{ Cukup Valid } \\
\hline \multirow{5}{*}{5} & \multirow{5}{*}{$\begin{array}{l}\text { Bahas } \\
\text { a }\end{array}$} & $\Sigma$ Skor & 12 & 13 \\
\hline & & $\begin{array}{l}\text { Skor } \\
\text { Maksimal }\end{array}$ & 16 & 16 \\
\hline & & $\bar{x}_{i}$ & 3 & 3,3 \\
\hline & & $\bar{x}$ & \multicolumn{2}{|c|}{3,125} \\
\hline & & Kriteria & \multicolumn{2}{|c|}{ Cukup Valid } \\
\hline
\end{tabular}

I. (Sumber Data: Hasil Angket)
2) Penilaian Angket Validasi Ahli Media Tahap 1

J. Tabel 6. (Hasil Penilaian Angket Validasi Tahap 1 Ahli Media)

\begin{tabular}{|c|c|c|c|c|}
\hline \multirow{2}{*}{ NO } & \multirow{2}{*}{$\begin{array}{l}\text { Kelayakan } \\
\text { Kegrafikan }\end{array}$} & \multirow[b]{2}{*}{ Analisis } & \multicolumn{2}{|c|}{ Validator } \\
\hline & & & $\begin{array}{c}\text { Valida } \\
\text { tor } 1\end{array}$ & $\begin{array}{c}\text { Valida } \\
\text { tor } 2\end{array}$ \\
\hline \multirow[t]{5}{*}{1} & \multirow{5}{*}{$\begin{array}{l}\text { Efisiensi } \\
\text { Media }\end{array}$} & $\Sigma$ Skor & 10 & 11 \\
\hline & & $\begin{array}{l}\text { Skor } \\
\text { Maksimal }\end{array}$ & 16 & 16 \\
\hline & & $\bar{x}_{i}$ & 2,5 & 2,75 \\
\hline & & $\bar{x}$ & \multicolumn{2}{|c|}{2,63} \\
\hline & & Kriteria & \multicolumn{2}{|c|}{ Cukup Valid } \\
\hline \multirow[t]{5}{*}{2} & \multirow{5}{*}{$\begin{array}{l}\text { Fungsi } \\
\text { Tombol }\end{array}$} & $\Sigma$ Skor & 5 & 6 \\
\hline & & $\begin{array}{l}\text { Skor } \\
\text { Maksimal }\end{array}$ & 8 & 8 \\
\hline & & $\bar{x}_{i}$ & 2,5 & 3 \\
\hline & & $\bar{x}$ & \multicolumn{2}{|c|}{2,75} \\
\hline & & Kriteria & \multicolumn{2}{|c|}{ Cukup Valid } \\
\hline \multirow[t]{5}{*}{3} & \multirow[t]{5}{*}{ Grafis } & $\Sigma$ Skor & 15 & 16 \\
\hline & & $\begin{array}{l}\text { Skor } \\
\text { Maksimal }\end{array}$ & 24 & 24 \\
\hline & & $\bar{x}_{i}$ & 2,5 & 2,67 \\
\hline & & $\bar{x}$ & \multicolumn{2}{|c|}{2,58} \\
\hline & & Kriteria & \multicolumn{2}{|c|}{ Cukup Valid } \\
\hline
\end{tabular}

K. (Sumber Data: Hasil Angket)

3) Revisi Pembuatan Media

Memperbaiki bagian menu program yang link salah pengkodean sehingga tidak sinkron. Pada menu Peta Konsep yang harusnya diklik masuk ke bagian Peta Konsep, tetapi malah masuk ke bagian Glosarium. 
Catur Andiyanto, Santhy Hawanti, Kuntoro

Pengembangan E-Modul Pengayaan Materi Debat Berbasis Software Sigil untuk Pembelajaran Bahasa Indonesia Kelas X SMA di Purbalingga

Gambar 3. (Tampilan Menu e-

\begin{tabular}{|l|}
\hline \multicolumn{1}{|c|}{ DAFTAR ISI } \\
\hline PENYUSUN E-MODUL \\
DAFTAR ISI \\
GLOSARIUM \\
PETA KONSEP \\
\hline
\end{tabular}

Gambar 4. (Tampilan sebelum direvisi/ Pengkodean yang salah)

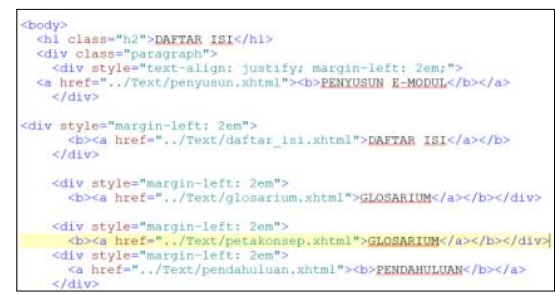

Gambar 5. (Tampilan sesudah direvisi/ Pengkodean yang benar)

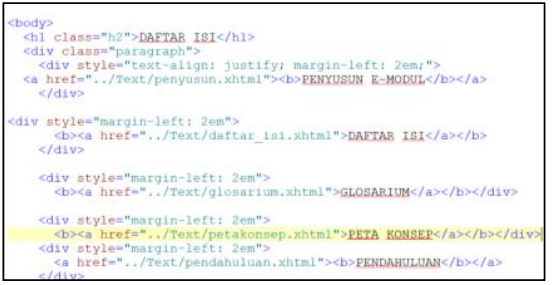

Memperbaiki programnya agar keluar masuknya lebih mudah dengan cara mengurangi spesifikasi video yang tadinya besar diturunkan atau dicompress menjadi lebih sedikit spesifikasi videonya.

Gambar 6. (Contoh tampilan video yang mempengaruhi beratnya program)

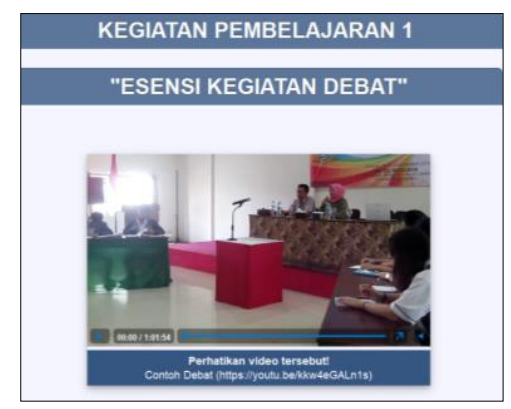

Gambar 7. (Sebelum dicompress)

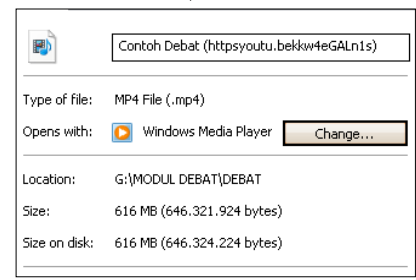

Gambar 8. (Sesudah dicompress)

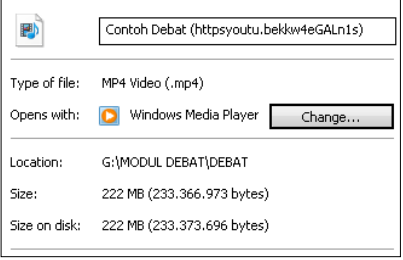

Pada bagian struktur tombolnya perlu diperbaiki agar lebih mudah dengan ditambah tombol menu Daftar Isi di bagian akhir setiap BAB untuk mempermudah ketika akan menuju ke $\mathrm{BAB}$ materi lain.

Gambar 9. (Sebelum direvisi)

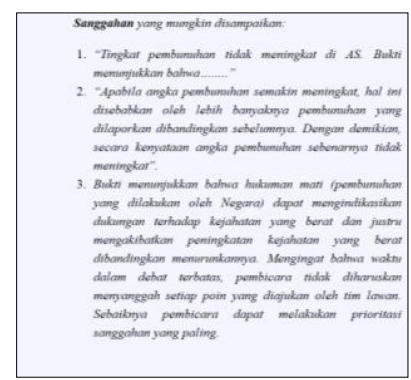

Gambar 10. (Sesudah direvisi)

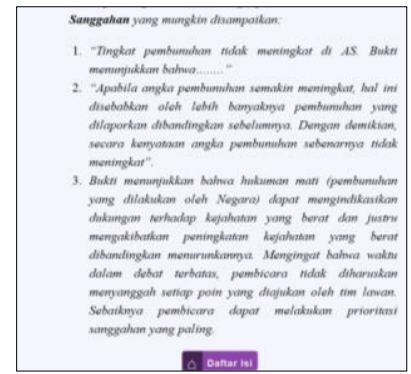

Pada halaman sampul perlu perbaikan kesesuaian pemilihan background, kesesuaian warna, kemenarikan sajian gambar agar lebih indah dilihat dengan pengeditan menggu- 
nakan sofware corel draw dan perbaikannya seperti berikut ini.

Gambar 11.

Gambar 12.

(Sebelum direvisi) (Sesudah
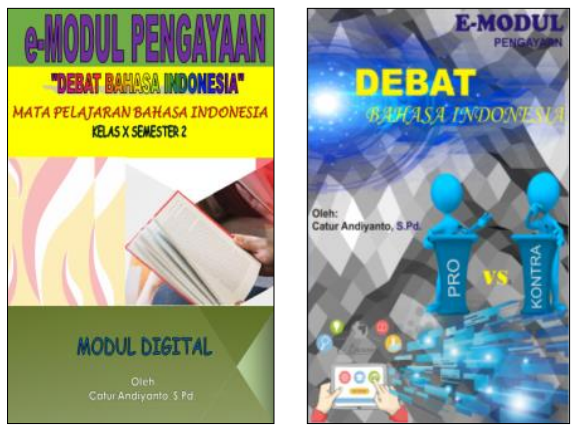

\section{d. Hasil Penilaian Angket Validasi}

Tahap 2

1) Penilaian Angket Validasi Ahli

Materi Tahap 2

Tabel 7. (Hasil Penilaian Angket

Validasi Tahap 2 oleh Ahli

Materi)

\begin{tabular}{|c|c|c|c|c|}
\hline \multirow[b]{2}{*}{$\mathrm{NO}$} & \multirow[b]{2}{*}{ Aspek } & \multirow[b]{2}{*}{ Analisis } & \multicolumn{2}{|c|}{ Validator } \\
\hline & & & $\begin{array}{c}\text { Valida } \\
\text { tor } 1\end{array}$ & $\begin{array}{c}\text { Valida } \\
\text { tor } 2\end{array}$ \\
\hline \multirow[t]{5}{*}{1} & \multirow{5}{*}{$\begin{array}{l}\text { Kesesuaian } \\
\text { materi }\end{array}$} & $\Sigma$ Skor & 7 & 8 \\
\hline & & $\begin{array}{l}\text { Skor } \\
\text { Maksimal }\end{array}$ & 8 & 8 \\
\hline & & $\bar{x}_{i}$ & 3,5 & 4 \\
\hline & & $\bar{x}$ & \multicolumn{2}{|c|}{3,75} \\
\hline & & Kriteria & \multicolumn{2}{|c|}{ Valid } \\
\hline \multirow[t]{5}{*}{2} & \multirow{5}{*}{$\begin{array}{l}\text { Keakurata } \\
\text { n materi }\end{array}$} & $\Sigma$ Skor & 18 & 18 \\
\hline & & $\begin{array}{l}\text { Skor } \\
\text { Maksimal }\end{array}$ & 20 & 20 \\
\hline & & $\bar{x}_{i}$ & 3,6 & 3,6 \\
\hline & & $\bar{x}$ & \multicolumn{2}{|c|}{3,6} \\
\hline & & Kriteria & \multicolumn{2}{|c|}{ Valid } \\
\hline \multirow[t]{2}{*}{3} & \multirow{2}{*}{$\begin{array}{l}\text { Mendoro } \\
\text { ng } \\
\text { Keinginta } \\
\text { huan }\end{array}$} & $\Sigma$ Skor & 7 & 8 \\
\hline & & $\begin{array}{l}\text { Skor } \\
\text { Maksimal }\end{array}$ & 8 & 8 \\
\hline
\end{tabular}

\begin{tabular}{|c|c|c|c|c|}
\hline & & $\bar{x}_{i}$ & 3,5 & 4 \\
\hline & & $\bar{x}$ & & \\
\hline & & Kriteria & & \\
\hline 4 & Teknik & $\Sigma$ Skor & 3 & 3 \\
\hline & penyajlan & $\begin{array}{l}\text { Skor } \\
\text { Maksimal }\end{array}$ & 4 & 4 \\
\hline & & $\bar{x}_{i}$ & 3 & 3 \\
\hline & & $\bar{x}$ & & \\
\hline & & Kriteria & & \\
\hline & & $\Sigma$ Skor & 15 & 15 \\
\hline 5 & Bahasa & $\begin{array}{l}\text { Skor } \\
\text { Maksimal }\end{array}$ & 16 & 16 \\
\hline & & $\bar{x}_{i}$ & 3,75 & 3,75 \\
\hline & & $\bar{x}$ & & \\
\hline & & Kriteria & & lid \\
\hline
\end{tabular}

(Sumber Data: Hasil Angket)

2) Penilaian Angket Validasi Ahli Media Tahap 2

Tabel 8. (Hasil Penilaian Angket Validasi Tahap 2 Ahli Media)

\begin{tabular}{|c|c|c|c|c|}
\hline \multirow{2}{*}{ NO } & \multirow{2}{*}{$\begin{array}{l}\text { Kelayakan } \\
\text { Kegrafikan }\end{array}$} & \multirow[b]{2}{*}{ Analisis } & \multicolumn{2}{|c|}{ Validator } \\
\hline & & & $\begin{array}{c}\text { Valida } \\
\text { tor } 1\end{array}$ & $\begin{array}{l}\text { Valida } \\
\text { tor } 2\end{array}$ \\
\hline \multirow[t]{5}{*}{1} & \multirow{5}{*}{$\begin{array}{l}\text { Efisiensi } \\
\text { Media }\end{array}$} & $\Sigma$ Skor & 13 & 14 \\
\hline & & $\begin{array}{l}\text { Skor } \\
\text { Maksimal }\end{array}$ & 16 & 16 \\
\hline & & $\bar{x}_{i}$ & 3,25 & 3,5 \\
\hline & & $\bar{x}$ & \multicolumn{2}{|c|}{3,38} \\
\hline & & Kriteria & \multicolumn{2}{|c|}{ Valid } \\
\hline \multirow[t]{5}{*}{2} & \multirow{5}{*}{$\begin{array}{l}\text { Fungsi } \\
\text { Tombol }\end{array}$} & $\Sigma$ Skor & 7 & 7 \\
\hline & & $\begin{array}{l}\text { Skor } \\
\text { Maksimal }\end{array}$ & 8 & 8 \\
\hline & & $\bar{x}_{i}$ & 3,5 & 3,5 \\
\hline & & $\bar{x}$ & \multicolumn{2}{|c|}{3,5} \\
\hline & & Kriteria & \multicolumn{2}{|c|}{ Valid } \\
\hline
\end{tabular}


Catur Andiyanto, Santhy Hawanti, Kuntoro

Pengembangan E-Modul Pengayaan Materi Debat Berbasis Software Sigil untuk Pembelajaran Bahasa Indonesia Kelas X SMA di Purbalingga

\begin{tabular}{|l|l|l|c|c|}
\hline 3 & Grafis & $\Sigma$ Skor & 17 & 18 \\
\cline { 3 - 5 } & & $\begin{array}{l}\text { Skor } \\
\text { Maksimal }\end{array}$ & 24 & 24 \\
\cline { 3 - 5 } & $\bar{x}_{i}$ & 2,83 & 3 \\
\hline & $\bar{x}$ & \multicolumn{2}{|c|}{2,91} \\
\cline { 3 - 5 } & & \multicolumn{2}{|c|}{ Cukup Valid } \\
\cline { 3 - 5 } & Kriteria & \multicolumn{2}{|c|}{24} \\
\hline
\end{tabular}

(Sumber Data: Hasi Angket)

3) Revisi Pembuatan Media

Pada bagian halaman sampul atau cover pada revisi pertama walaupun sudah lebih bagus dari awal pembuatan, tetapi masih perlu perbaikan lagi dalam hal kesesuaian pemilihan background, kesesuaian warna, kemenarikan sajian gambar agar lebih menarik lagi dengan pengeditan menggunakan sofware corel draw dan perbaikannya seperti berikut ini.

\section{Gambar $13 . \quad$ Gambar 14. \\ (Revisi pertama) (Revisi kedua)}

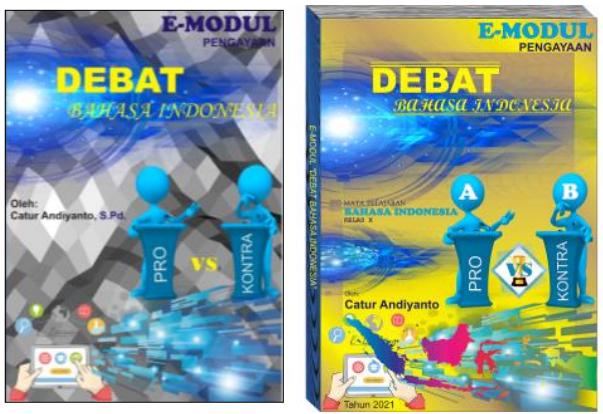

e. Hasil Penilaian Angket Validasi

Tahap 3

Tabel 9.

\begin{tabular}{|c|c|c|c|c|}
\hline \multirow{2}{*}{$\mathrm{NO}$} & \multirow{2}{*}{$\begin{array}{l}\text { Kelayakan } \\
\text { Kegrafikan }\end{array}$} & \multirow[b]{2}{*}{ Analisis } & \multicolumn{2}{|c|}{ Validator } \\
\hline & & & $\begin{array}{c}\text { Valida } \\
\text { tor } 1\end{array}$ & $\begin{array}{c}\text { Valida } \\
\text { tor } 2\end{array}$ \\
\hline \multirow[t]{3}{*}{1} & \multirow{3}{*}{$\begin{array}{l}\text { Efisiensi } \\
\text { Media }\end{array}$} & $\Sigma$ Skor & 14 & 14 \\
\hline & & $\begin{array}{l}\text { Skor } \\
\text { Maksimal }\end{array}$ & 16 & 16 \\
\hline & & $\bar{x}_{i}$ & 3,5 & 3,5 \\
\hline
\end{tabular}

\begin{tabular}{|c|c|c|c|c|}
\hline & & $\bar{x}$ & \multicolumn{2}{|c|}{3,5} \\
\hline & & Kriteria & \multicolumn{2}{|c|}{ Valid } \\
\hline \multirow[t]{5}{*}{2} & \multirow{5}{*}{$\begin{array}{l}\text { Fungsi } \\
\text { Tombol }\end{array}$} & $\Sigma$ Skor & 7 & 8 \\
\hline & & $\begin{array}{l}\text { Skor } \\
\text { Maksimal }\end{array}$ & 8 & 8 \\
\hline & & $\bar{x}_{i}$ & 3,5 & 4 \\
\hline & & $\bar{x}$ & \multicolumn{2}{|c|}{3,75} \\
\hline & & Kriteria & \multicolumn{2}{|c|}{ Valid } \\
\hline \multirow[t]{5}{*}{3} & \multirow[t]{5}{*}{ Grafis } & $\Sigma$ Skor & 19 & 22 \\
\hline & & $\begin{array}{l}\text { Skor } \\
\text { Maksimal }\end{array}$ & 24 & 24 \\
\hline & & $\bar{x}_{i}$ & 3,167 & 3,67 \\
\hline & & $\bar{x}$ & \multicolumn{2}{|c|}{3,42} \\
\hline & & Kriteria & \multicolumn{2}{|c|}{ Valid } \\
\hline
\end{tabular}

L. (Sumber Data: Hasil Angket)

\section{Tahap Implement (Implementasi)}

a Uji Efektivitas (Deskripsi Data Hasil Pretest dan Posttest)

Pada uji coba keefektifan, siswa diberikan tes berupa pretest dan posttest dengan melibatkan total 60 responden yaitu 20 responden pada X MIPA 5 dan 20 responden pada $X$ IPS 1 dari siswa SMA Negeri 1 Purbalingga dan 20 responden kelas $X$ MIPA 2 dari siswa SMA Negeri 1 Kutasari.

Tabel 10. (Data Hasil Perhitungan Pretest dan Posttest Kelas X MIPA 5 SMA Negeri 1 Purbalingga)

\begin{tabular}{|c|c|c|c|c|c|}
\hline $\begin{array}{c}\text { Jenis } \\
\text { Test }\end{array}$ & N & $\begin{array}{c}\text { Skor } \\
\text { Maksi } \\
\text { mum }\end{array}$ & $\begin{array}{c}\text { Skor } \\
\text { Minim } \\
\text { um }\end{array}$ & $\begin{array}{c}\text { Rata } \\
\text {-rata }\end{array}$ & $\begin{array}{c}\text { Standar } \\
\text { Deviasi }\end{array}$ \\
\hline Pretest & 20 & 80 & 40 & 64 & 62,98 \\
\hline Posttest & 20 & 100 & 60 & 83 & 81,896 \\
\hline
\end{tabular}


Catur Andiyanto, Santhy Hawanti, Kuntoro

Pengembangan E-Modul Pengayaan Materi Debat Berbasis Software Sigil untuk Pembelajaran Bahasa Indonesia Kelas X SMA di Purbalingga

Tabel 11. (Data Hasil Perhitungan

Pretest dan Posttest Kelas X IPS 1

SMA Negeri 1 Purbalingga)

\begin{tabular}{|l|c|c|c|c|c|}
\hline $\begin{array}{c}\text { Jenis } \\
\text { Test }\end{array}$ & N & $\begin{array}{c}\text { Skor } \\
\text { Maksi } \\
\text { mum }\end{array}$ & $\begin{array}{c}\text { Skor } \\
\text { Minim } \\
\text { um }\end{array}$ & $\begin{array}{c}\text { Rata } \\
\text {-rata }\end{array}$ & $\begin{array}{c}\text { Standar } \\
\text { Deviasi }\end{array}$ \\
\hline Pretest & 20 & 80 & 40 & 63 & 62,64 \\
\hline Posttest & 20 & 100 & 60 & 81 & 79,213 \\
\hline
\end{tabular}

Tabel 12. (Data Hasil Perhitungan

Pretest dan Posttest Kelas X MIPA 2

SMA Negeri 1 Kutasari)

\begin{tabular}{|l|c|c|c|c|c|}
\hline $\begin{array}{c}\text { Jenis } \\
\text { Test }\end{array}$ & N & $\begin{array}{c}\text { Skor } \\
\text { Maksi } \\
\text { mum }\end{array}$ & $\begin{array}{c}\text { Skor } \\
\text { Minim } \\
\text { um }\end{array}$ & $\begin{array}{c}\text { Rata } \\
\text {-rata }\end{array}$ & $\begin{array}{c}\text { Standar } \\
\text { Deviasi }\end{array}$ \\
\hline Pretest & 20 & 80 & 40 & 62 & 61,42 \\
\hline Posttest & 20 & 100 & 60 & 81 & 79,7212 \\
\hline
\end{tabular}

Berdasarkan data pada lampiran diperoleh hasil perhitungan menggunakan effect size pada kelas $X$ MIPA 5 nilai $E_{s}=0,266$, pada kelas X IPS 1 nilai $E_{S}=0,245$, dan pada kelas $X$ MIPA 2 nilai $E_{S}=$ 0,266 . Berdasarkan kategori yang ditentukan tingkat efektivitasnya maka pembelajaran menggunakan $e$ modul berbantuan sigil software pada materi debat bahasa Indonesia dikategorikan cukup efektif dan dapat digunakan dalam proses pembelajaran.

\section{b. Uji Kemenarikan Produk}

Uji kemenarikan produk $e$ modul ini dilakukan pada uji coba skala kecil dan uji coba skala besar. Skala Kecil melibatkan total 15 siswa yaitu 5 responden pada kelas $\mathrm{X}$ MIPA 5 dan 5 responden pada X IPS 1 dari SMA Negeri 1 Purbalingga dan 5 responden pada kelas X MIPA 2 dari SMA Negeri 1 Kutasari. Hasil uji coba skala kecil di SMA Negeri 1 Purbalingga pada kelas X MIPA 5 diperoleh rata-rata nilai 3,45 pada kriteria "Sangat Menarik" dan kelas
X IPS 1 diperoleh rata-rata nilai 3,43 pada kriteria "Sangat Menarik". Kemudian hasil uji coba skala kecil di SMA Negeri 1 Kutasari pada kelas $X$ MIPA 2 diperoleh rata-rata nilai 3,46 pada kriteria "Sangat Menarik". Sehingga rata-rata uji coba skala kecil kemenarikannya adalah 3,44 pada kriteria "Sangat Menarik". Dengan begitu penulis menyimpulkan bahwa e-modul yang dikembangkan layak digunakan selama proses pembelajaran.

Selanjutnya pada uji coba skala besar dengan melibatkan total 60 responden yaitu 20 responden pada X MIPA 5 dan 20 responden pada $X$ IPS 1 dari siswa SMA Negeri 1 Purbalingga dan 20 responden kelas $\mathrm{X}$ MIPA 2 dari siswa SMA Negeri 1 Kutasari untuk mengetahui kemenarikan e-modul secara luas. Hasil analisis data uji skala besar dari SMA Negeri 1 Purbalingga pada X MIPA 5 yaitu 3,49 pada kriteria "Sangat Menarik" dan X IPS 1 yaitu 3,46 pada kriteria "Sangat Menarik" sedangkan dari SMA Negeri 1 Kutasari pada kelas X MIPA 2 yaitu 3,47 pada kriteria "Sangat Menarik". Sehingga rata-rata uji coba skala besar kemenarikannya adalah 3,47 pada kriteria "Sangat Menarik".

\section{Tahap Evaluation (Evaluasi)}

Evaluasi Perbandingan tahapan uji coba didasarkan dari data hasil implementasi uji coba respon skala kecil dan besar pada kelas X MIPA 5, X IPS 1 dan X MIPA 2 terlihat pada gambar grafik berikut ini:

Gambar 16. (Grafik Perbandingan Uji

Skala Kecil dan Skala Besar Setiap

Kelas) 


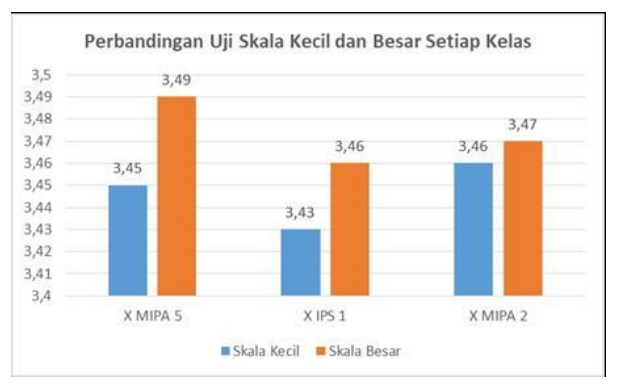

Sedangkan Evaluasi Perbandingan ratarata total kelas pada uji coba skala kecil dan besar terlihat pada gambar grafik berikut ini:

\section{Gambar 17. (Grafik Perbandingan}

Rata-rata Total Kelas Uji Skala Kecil dan Skala Besar)

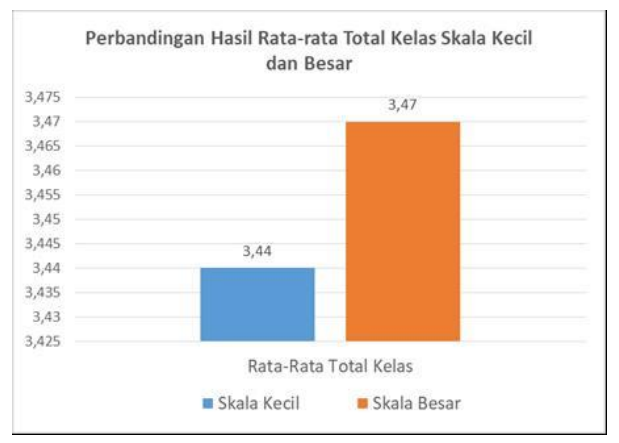

\section{M.Pembahasan}

1. Hasil Analisis Kebutuhan Peserta Didik dan Guru dalam Pengembangan E-Modul Pengayaan Materi Debat Berbasis Software Sigil untuk Pembelajaran Bahasa Indonesia Kelas X SMA di Purbalingga

Analisis kebutuhan Peserta Didik dapat dilihat pada lembar wawancara awal kebutuhan peserta didik yang diperoleh hasil pada 15 responden terlihat bahwa sebanyak 73,3 \% menjawab perlu, 6,7 \% menjawab lumayan perlu, dan $20 \%$ menjawab sangat perlu sumber belajar lain selain buku cetak. Sebanyak $80 \%$ siswa ternyata membutuhkan gambar dan video contoh praktik berdebat dan yang
$20 \%$ siswa menjawab sangat membutuhkan. Alasan siswa membutuhkan gambar dan video itu agar materi debat lebih mudah dipahami, ada gambaran tentang contoh debat dan dapat mempraktikan debat dengan cara yang benar. Sebanyak 66,7 $\%$ siswa membutuhkan e-modul yang dilengkapi foto dan video yang tidak hanya dapat diakses online tetapi juga offline dan yang 33,3\% siswa menjawab sangat membutuhkan. Alasan dari siswa adalah agar hemat kuota, tidak terkendala sinyal, dan dapat diakses kapanpun. Sebanyak 86,8 \% siswa membutuhkan e-modul yang tidak hanya dibuka dengan komputer tetapi juga dengan android, 6,6 \% siswa menjawab agak membutuhkan, dan 6,6 $\%$ siswa menjawab sangat membutuhkan. Alasan siswa karena lebih praktis, lebih mudah, mudah dibuka, dan lebih sering dibawa.

Analisis kebutuhan guru dilaksanakan dengan menyebarkan angket kepada empat guru dari dua sekolah. Berdasarkan hasil sampel guru yang mengisi angket menyatakan $100 \%$ guru tersebut menjawab bahwa media pembelajaran yang sekarang digunakan guru belum cukup atau tidak cukup hanya menggunakan buku paket tercetak. Alasan guru tersebut karena perkembangan zaman sekarang ini perlu inovasi dan gabungan teknologi sehingga perlu tambahan media lain. Selain itu kalau hanya dengan menggunakan buku paket tercetak ternyata belum membuat peserta didik mudah memahami materi bahasa Indonesia khususnya materi debat dengan hasil yang memuaskan. Alasan guru mengapa perlu ada tambahan media pembelajaran selain buku paket 
tercetak dalam memahami materi debat bahasa Indonesia adalah agar pembelajaran lebih menarik karena materi debat perlu adanya praktik. Sebanyak $75 \%$ guru menyatakan bahwa materi debat selain teori juga sangat perlu atau perlu sekali adanya gambar dan video contoh dalam praktik berdebat dan yang $25 \%$ menyatakan perlu. Alasannya karena siswa harus melihat contoh video dan gambar agar dapat mempraktikan dan agr lebih paham gambaran mengenai debat. Sebanyak $75 \%$ guru menyatakan bahwa guru perlu sekali media berupa $e$ modul yang dilengkapi foto dan video yang dapat diakses tidak hanya online tetapi juga ketika offline dan yang $25 \%$ menyatakan perlu. Sebanyak $100 \%$ guru menyatakan bahwa guru perlu media berupa e-modul yang tidak hanya dapat dibuka dengan komputer tetapi juga dengan andriod. Guru menyatakan bahwa siswa lebih termotivasi untuk memahami materi debat apabila tersedia $e$-modul yang dilengkapi foto dan video yang dapat diakses ketika offline dan dapat dibuka tidak hanya dengan komputer tetapi juga dengan andriod.

Berdasarkan hasil angket analisis kebutuhan siswa dan guru tersebut dapat disimpulkan bahwa kurangnya ketertarikan peserta didik terhadap pembelajaran materi debat bahasa Indonesia karena pembelajaran yang monoton hanya menggunakan buku paket tercetak sebagai media pembelajaran. Selain itu guru bahasa Indonesia juga membutuhkan media pembelajaran yang menarik agar peserta didiklebih termotivasi untuk memahami materi debat dengan adanya e-modul yang dilengkapi foto dan video yang dapat diakses tidak hanya online tetapi juga ketika offline dan dapat dibuka tidak hanya dengan komputer tetapi juga dengan andriod.

2. Proses pengembangan E-Modul Pengayaan Materi Debat Berbasis Software Sigil untuk Pembelajaran Bahasa Indonesia Kelas X SMA di Purbalingga

Proses pengembangan E-Modul Pengayaan Materi Debat Berbasis Software Sigil untuk Pembelajaran Bahasa Indonesia Kelas X SMA di Purbalingga dijelaskan secara rinci di tahap Design dan tahap Development. Dalam menyusun design kerangka produk, sistematika penyajian materi dan instrument disesuaikan dengan kompetensi dasar. Bahan ajar yang dikembangkan adalah e-modul dengan berbantuan Sigil Software pada materi debat bahasa Indonesia. Penyesuaian materi dan gambar pada tampilan $e$ modul yang dikembangkan sebelumnya dikonsep pada tahap design oleh peneliti kemudian dievaluasi kembali.

Pada tahap development merupakan tahap pembuatan perangkat pembelajaran dan proses validasi. Dalam tahap pengembangan, yaitu merealisasikan kerangka yang masih konseptual menjadi produk utuh. Produk yang sudah selesai selanjutnya dievaluasi oleh para pakar dan praktisi pendidikan sebagai validator yang terdiri dari ahli materi adalah Dr. Kuntoro, M. Hum. dan Dewi Maryanti, S.Pd., M.Pd. Sedangkan ahli media adalah Andriani Suzana, M.Pd. dan Rudi Budi Triandoyo, S.Kom. Hasil penilaian ahli materi diperoleh rata-rata skor 3,68 dan penilaian ahli media dengan skor rata-rata 3,50. Keduanya memiliki kriteria interprentasi Sangat 
Baik. E-modul yang dikembangkan memenuhi kriteria valid sehingga dapat disimpulkan e-modul tersebut layak digunakan.

3. Kualitas E-Modul Pengayaan Materi Debat Berbasis Software Sigil untuk Pembelajaran Bahasa Indonesia Kelas X SMA di Purbalingga

Kualitas E-Modul Pengayaan Materi Debat Berbasis Software Sigil untuk Pembelajaran Bahasa Indonesia Kelas X SMA di Purbalingga dijelaskan secara rinci di tahap Implemenation dan tahap Evaluation. Pada tahap Implementation (Implementasi) dilakukan beberapa kegiatan yaitu, uji coba skala kecil dan uji coba skala besar untuk mengetahui kemenarikan modul dengan menyebarkan angket respon siswa. Hasil uji kemenarikan $E$ Modul dapat dilihat dari angket respon siswa yang sudah dibagikan dan mendapatkan hasil rata-rata hasil uji coba skala kecil dari SMA Negeri 1 Purbalingga pada kelas X MIPA 5 hasil rata-ratanya 3,45 dan pada kelas X IPS 1 hasil rata-ratanya 3,43, sedangkan dari SMA Negeri 1 Kutasari pada kelas X MIPA 2 hasil rata-ratanya 3,43. Sehingga total rata-rata uji coba kemenarikan pada skala kecil adalah 3,43 pada kriteria "Sangat Menarik". Selanjutnya hasil analisis data uji skala besar dari SMA Negeri 1 Purbalingga pada kelas X MIPA 5 yaitu 3,49 dan pada kelas X IPS 1 yaitu 3,46, sedangkan dari SMA Negeri 1 Kutasari pada kelas X MIPA 2 yaitu 3,47, sehingga total rata-rata uji skala besar adalah 3,47 dengan kriteria "sangat menarik". Berdasarkan hasil tersebut dapat ditarik kesimpulan bahwa $E$ Modul yang dikembangkan telah memenuhi aspek kemenarikan sehingga layak untuk diimplementasikan kepada siswa kelas X SMA di Purbalingga.

Keefektifan e-modul dapat dilihat dari hasil tes kemampuan belajar siswa kelas X SMA di Purbalingga dengan memberikan pretest dan posttest. Hasil pengujian hipotesis pada SMA Negeri 1 Purbalingga pada kelas X MIPA 5 yaitu 0,266 dan pada kelas X IPS 1 yaitu 0,245 sedangkan dari SMA Negeri 1 Kutasari pada kelas X MIPA 2 yaitu 0,266 dengan hasil totalnya tergolong cukup efektif. Berdasarkan kategori yang ditentukan tingkat efektivitasnya maka pembelajaran menggunakan $e$ modul berbantuan sigil software pada materi debat bahasa Indonesia dikategorikan cukup efektif karena ratarata tes hasil belajar siswa sesudah menggunakan e-modul lebih tinggi dari rata-rata kemampuan hasil belajar siswa sebelum memakai e-modul.

4. Respon Guru terhadap Pengembangan E-Modul Pengayaan Materi Debat Berbasis Software Sigil untuk Pembelajaran Bahasa Indonesia Kelas X SMA di Purbalingga

Respon Guru setelah proses Pengembangan E-Modul Pengayaan Materi Debat Berbasis Software Sigil untuk Pembelajaran Bahasa Indonesia Kelas X SMA di Purbalingga didasarkan pada hasil uji coba yang diikuti oleh 4 responden yang terdiri dari 2 guru bahasa Indonesia SMA Negeri 1 Purbalingga dan 2 guru bahasa Indonesia SMA Negeri 1 Kutasari. Pada hasil uji coba diperoleh hasil rata-rata total uji coba kemenarikan adalah 3,85 dan termasuk kriteria "Sangat Menarik".

5. Respon Peserta Didik terhadap Pengembangan E-Modul Pengayaan 
Catur Andiyanto, Santhy Hawanti, Kuntoro

Pengembangan E-Modul Pengayaan Materi Debat Berbasis Software Sigil untuk Pembelajaran Bahasa

Indonesia Kelas X SMA di Purbalingga

\section{Materi Debat Berbasis Software Sigil untuk Pembelajaran Bahasa Indonesia Kelas X SMA di Purbalingga}

Respon Peserta Didik setelah proses Pengembangan E-Modul Pengayaan Materi Debat Berbasis Software Sigil untuk Pembelajaran Bahasa Indonesia Kelas X SMA di Purbalingga didasarkan pada hasil uji coba skala kecil yang diikuti oleh 15 responden berasal dari SMA Negeri 1 Purbalingga dan SMA Negeri 1 Kutasari diperoleh hasil rata-rata total uji coba kemenarikan skala kecil adalah 3,43 dan termasuk kriteria "Sangat Menarik". Pada uji coba skala besar yang diikuti oleh 60 responden berasal dari SMA Negeri 1 Purbalingga dan SMA Negeri 1 Kutasari diperoleh hasil rata-rata total uji coba kemenarikan skala besar adalah 3,47 dan termasuk kriteria "Sangat Menarik".

\section{KESIMPULAN}

Penelitian dan pengembangan ini menghasilkan sebuah produk yakni E- Modul yang mengacu pada rancangan penelitian dan pengembangan yang dimodifikasi dari model pengembangan ADDIE. Materi yang dibahas pada modul ini adalah materi debat bahasa Indonesia.

Hasil angket validasi dan respon siswa mengenai kelayakan dan kemenarikan E-Modul diperolah rata-rata 3,68 oleh ahli materi, dan 3,50 oleh ahli media. Hasil angket respon siswa skala kecil pada 3 kelas yaitu 5 responden kelas X MIPA 5 dan 5 responden X IPS 1 dari SMA Negeri 1 Purbalingga dan 5 responden kelas X MIPA 2 dari SMA Negeri 1 Kutasari diperoleh total rata-rata pada skala kecil adalah 3,43 pada kriteria "Sangat Menarik". Sedangkan hasil angket respon siswa skala besar pada 3 kelas tersebut yaitu
20 responden pada kelas X MIPA 5 dan 20 responden $X$ IPS 1 dari SMA Negeri 1 Purbalingga dan 20 responden kelas X MIPA 2 dari SMA Negeri 1 Kutasari diperoleh total rata-rata pada skala besar adalah 3,47 dengan kriteria "sangat menarik".

Hasil uji effect size di kelas X MIPA 5 diperoleh 0,266 dengan kategori efektivitas yaitu cukup efektif dan kelas X IPS 1 diperoleh 0,245 dengan kategori efektivitas yaitu cukup efektif pada SMA Negeri 1 Purbalingga, sedangkan hasil uji effect size di kelas X MIPA 2 diperoleh 0,266 dengan katergori cukup efektif pada SMA Negeri 1 Kutasari. Dari data tersebut diketahui bahwa E-Modul yang dikembangkan layak dan efektif digunakan sebagai bahan ajar untuk membantu siswa dalam proses pembelajaran.

\section{DAFTAR PUSTAKA}

Aryo, Foy. 2020. Modul Pembelajaran SMA Bahasa Indonesia Berdebat Secara Santun. Jakarta: Kementerian Pendidikan dan Kebudayaan Republik Indonesia.

Daryanto. 2013. Media Pembelajaran: Peranannya Sangat Penting dalam Mencapai Tujuan Pembelajaran. Yogyakarta: Gava Media.

Fitri, Anisa, Netriwati, dan Siska Andriani. 2021. Sigil Software sebagai Pengembangan E-Modul Pembelajaran Matematika. Journal of Mathematics Education. p-ISSN 2477-409X, eISSN: 2549-9084. Progam Studi Pendidikan Matematika, UIN Raden Intan Lampung. https://www. researchgate.net/publication /351 313851 Sigil_Softwaresebagai_Pengem bangan_EModul_Pembelajaran_Matematika. (Diakses 10 Maret 2021). 
Ghanoe, MD. 2020. Seni Memenangkan Debat. Yogyakarta: Alaska.

Kunandar. 2013. Penilaian Autentik (Penilaian Hasil Belajar Peserta Didik Berdasarkan Kurikulum 2013) Suatu Pendekatan Praktis Disertai dengan Contoh Edisi Revisi. Jakarta: PT Raja Grafindo Persada.

Lilly, Emily L. 2012. Assigned Positions for In-Class Debates Influence Student Opinions. International Journal of Teaching and Learning in Higher Education, Volume 24, Number 1, 15, ISSN 1812-9129. Virginia Military Institute. Alailable at http://www.isetl.org/ijtlhe/ . (Diakses 17 Maret 2021).

Pratama, Ramadhana Agung, Saida Ulfa, and Dedi Kuswandi. 2018 'Mobile Learning Berbasis Game Based Learning Pelajaran Matematika Pokok Bahasan Bangun Ruang Sisi Datar', Teori Penelitian Dan Pengembangan. (Diakses 10 Maret 2021).

Rusdi. 2018. Penelitian Desain dan Pengembangan Kependidikan: Konsep, Prosedur dan Sintesis Pengetahuan Baru. Jakarta: PT Raja Grafindo Persada.

Schopenhauer, Arthur. 2020. Seni Berdebat: 38 Jurus Memenangkan Argumen. Yogyakarta: Circa.

Sugiyono. 2013. Metode Penelitian Pendidikan (Pendekatan Kuantitatif, Kualitatif, dan $R \& D)$. Bandung: Alfabeta.

Suryani, Nunuk. Achmad Setiawan, dan Aditin Putria. 2018. Media Pembelajaran Inovatif dan Pengembangannya. Bandung: PT Remaja Rosdakarya.

Uno, Hamzah B. Sutardjo Atmowidjoyo, dan Nina Lamatenggo. 2018. Pengembangan Kurikulum Rekayasa
Pedagogik dalam Pembelajaran. Jakarta: PT Raja Grafindo Persada.

Wahyudin. 2018. Komputer dan Masyarakat. Bandung: PT Alfabeta. 